\title{
O CONCEITO DE VALORAÇÃO NOS ESTUDOS DO CÍRCULO DE BAKHTIN: A INTER-RELAÇÃO ENTRE IDEOLOGIA E LINGUAGEM
}

\author{
Rodrigo Acosta Pereira* \\ Rosângela Hammes Rodrigues** \\ Universidade Federal de Santa Catarina \\ Florianópolis, Santa Catarina, Brasil
}

\begin{abstract}
Resumo: O presente ensaio objetiva discutir o conceito de valoração nos escritos do Círculo de Bakhtin. Para tanto, revisitamos as obras do Círculo, procurando demonstrar a relação constitutiva desse conceito com os de ideologia e linguagem. A pesquisa nos conduz a entender a valoração como índices sociais de valor e a ideologia como o horizonte axiológico do discurso, além de entender os enunciados e os gêneros como materialização da valoração e da ideologia. O estudo constrói-se essencialmente por meio de revisão bibliográfica e busca colaborar para o entendimento do conceito de valoração e sua relação com os de ideologia e linguagem, dentre outros que se engendram na obra bakhtiniana.
\end{abstract}

Palavras-chave: Círculo de Bakhtin. Valoração. Ideologia. Linguagem.

1 INTRODUÇÃO

Este trabalho objetiva apresentar uma discussão teórico-analítica acerca do conceito de valoração nos estudos do Círculo de Bakhtin. Considerando sua abrangência na obra do Círculo, circunscrevemos sua análise na relação com outros conceitos desenvolvidos pelo grupo e que consideramos relevantes para a compreensão do seu modo de funcionamento no discurso, a saber: ideologia, linguagem, enunciado, gêneros do discurso, cronotopo e dialogismo.

Na primeira seção apresentamos o conceito de valoração e sua relação com o de ideologia e linguagem. Nas subsequentes, analisamos o funcionamento e a materialização da valoração no discurso, por meio da abordagem dos conceitos de enunciado, gêneros do discurso, cronotopo e dialogismo.

Consideramos que a análise não é exaustiva, uma vez que a valoração pode ser relacionada a outros conceitos, mas que atinge acabamento no que se refere à interrelação entre linguagem e ideologia, mediada pela valoração, tal qual indicado no subtítulo do ensaio.

\footnotetext{
* Professor do Programa de Pós-graduação em Linguística da UFSC. Doutor em Linguística. Email: drigo_acosta@yahoo.com.br

** Professora do Programa de Pós-graduação em Linguística da UFSC. Doutora em Linguística Aplicada. Email: hammes@cce.ufsc.br
} 


\title{
2 A IDEOLOGIA E O HORIZONTE AXIOLÓGICO DOS DISCURSOS
}

O Círculo de Bakhtin buscava explicitamente, a partir da segunda metade da década de 1920, construir uma teoria materialista da criação linguístico-ideológica. O Círculo procurava compreender como os discursos, materializados nos enunciados, sejam eles das esferas da vida cotidiana, sejam eles das esferas formalizadas e sistematizadas, são saturados e refratados pela ideologia, e como essa relação entre ideologia e linguagem se constitui. Por exemplo, em Marxismo e filosofia da linguagem, o Círculo apresenta a proposição da construção ideológica da consciência, bem como "as diretrizes gerais para um estudo de base materialista e sócio-histórica do universo da criação ideológica.” (FARACO, 2003, p. 46). E é a partir dessa relação que os autores desenvolvem o conceito de valoração.

Nesse contexto, observa-se o postulado da não neutralidade dos discursos, uma vez que estes são sempre marcados pela valoração de uma dada ideologia. Inicialmente, importa salientar que, pela ancoragem filosófico-epistemológica do Círculo, a concepção de valoração não encontra eco nos estudos idealistas do fim do século XIX e do início do século XX.

No texto Les frontières entre poétique et linguistique, Volochinov alerta o leitor sobre a questão:

\begin{abstract}
A fim de evitar mal entendidos, parece-nos necessário destacar que aquilo que entendemos por "valor" não tem nada a ver com a concepção idealista que era corrente na Psicologia (ver Münsterberg) e na Filosofia (ver Rickert) no final do século XIX e início do século $\mathrm{XX}$. Nós operamos com o conceito de valor ideológico, que não objetiva a nenhuma "universalidade", mas que carrega uma significação social e, mais precisamente, uma significação de classe. ${ }^{1}$ (VOLOSHINOV ${ }^{2}, 1981$ [1930], p. 254, grifos do autor).
\end{abstract}

Como podemos observar, a noção de valoração é de base ideológica, o que nos leva à necessidade de compreensão do conceito de ideologia e sua relação com a linguagem. Embora esse conceito seja fundante e perpasse toda a obra do Círculo, tal qual acontece com outros conceitos, tratados na sua inter-relação (e não na sua definição isolada e acabada), com vistas a construí-los no movimento das práticas discursivas e da sua formulação teórica, poucas vezes vamos encontrar uma definição acabada e isolada de ideologia.

Em ¿Que és el lenguaje?, Volochinov afirma que

\footnotetext{
1 “Afin d'éviter les malentendus, il nous parait nécessaire de souligner que ce que nous entendons par "valeur" n'a rien à voir avec la conception idéaliste qui était courante à la fin du XIX ${ }^{\mathrm{e}}$ siècle et au début $\mathrm{du} \mathrm{XX}^{\mathrm{e}}$ siècle en psychologie (voir Münsterberg) et en philosophie (voir Rickert). Nous opérons avec le concept de valeur idéologique, qui ne prétend à aucune "universalité", mais porte une signification sociale et même, plus précisément, une signification de classe. »

2 Nas referências mantivemos a grafia e o nome do autor do texto tais quais atribuídos pelo tradutor. Sobre a questão da autoria, consideramos, seguindo a concepção discursiva de autoria proposta pelo grupo, o Círculo de Bakhtin como autor dos textos.
} 
Por ideologia entendemos a totalidade das reflexões e interpretações da realidade social e natural que acontecem no cérebro do homem, materializados por meio de palavras, desenhos, diagramas ou outras formas sígnicas ${ }^{3}$. (1993[1929], p. 224, grifos do autor).

Se em outros momentos da obra vamos percebendo a noção de ideologia relacionada (não direta e mecanicamente) à estrutura sociopolítica e econômica da sociedade, bem como a apresentação de seu caráter criativo, nessa citação observamos, em primeiro lugar, a dimensão semiótico-interpretativa da ideologia, tal qual já sinalizada em Marxismo e filosofia da linguagem: "Tudo que é ideológico possui um valor semiótico." (VOLOCHINOV, 1988[1929], p. 32, grifos do autor).

Em segundo lugar, percebemos nessa citação a relação constitutiva da ideologia com a linguagem. Para Volochinov (1988[1929]), os fenômenos ideológicos não podem ser reduzidos às particularidades da consciência e do psiquismo; eles possuem uma encarnação material (som, massa física, cor movimento do corpo etc.), ou seja, eles possuem uma realidade sígnica. Por isso, o domínio ideológico coincide com o domínio dos signos, sendo mutuamente correspondentes. "A realidade dos fenômenos ideológicos é a realidade objetiva dos signos.” (p. 36).

Como Miotello (2008[2001]) comenta ao discutir essa definição de ideologia, percebe-se que ela não é compreendida como "falsa consciência" - tal qual entendida pelo marxismo oficial - ou como expressão de uma ideia - o que remeteria à noção de ideologia como "consciência individual" -, mas como a expressão de uma tomada de posição determinada.

Segundo Volochinov (1988[1929]), a ideologia do cotidiano corresponde à totalidade da atividade mental centrada sobre a vida cotidiana, assim como a expressão que a ela se liga, ambas de natureza social, e que não correspondem a um sistema ideológico formalizado e sistematizado. Já os sistemas ideológicos formalizados, como o da ciência, da moral, da arte, da religião etc., constituem-se a partir da ideologia do cotidiano e, uma vez constituídos, exercem forte influência sobre esta, dando-lhe o seu tom. Por outro lado, a seiva da existência da ideologia formalizada e sistematizada é a ideologia do cotidiano, uma vez que a avaliação crítica de toda produção ideológica opera-se na/por essa ideologia. "Esta coloca a obra ${ }^{4}$ numa situação social determinada. [...] A obra é interpretada [por meio da interação social] no espírito desse conteúdo da consciência [...] e recebe dela uma nova luz. É nisso que reside a vida da obra ideológica." (p. 119).

Ainda, o autor salienta que "aquilo mesmo que torna o[s] signo[s] ideológico[s] vivo[s] e dinâmico[s], faz dele[s] um instrumento de refração e de deformação do ser" (1988[1929], p. 47), uma vez que a classe dominante tende a conferir-lhes um caráter inatingível e acima das classes/grupos sociais, a fim de ocultar/abafar a luta dos índices sociais de valor que neles se travam e de apagar a plurivalência dos signos, apresentando-os como monovalentes.

\footnotetext{
${ }^{3}$ Por ideologia entendemos todo el conjunto de los reflejos y de las interpretaciones de la realidad social y natural que suceden en el cérebro del hombre, fijados por medio de palabras, diseños, esquemas, u otras formas sígnicas.

${ }^{4} \mathrm{O}$ autor está tratando como exemplo uma criação ideológica da esfera da arte, isto é uma obra de arte. Neste ensaio, usamos o termo obra também para nos referirmos ao conjunto dos textos do Círculo de Bakhtin.
} 
Um exemplo desse apagamento/ocultamento da plurivalência dos signos como lugar de se observar o trabalho da ideologia e da valoração que lhe é correspondente pôde ser visto em 2011, no âmbito do discurso jornalístico, no que se refere à concepção de língua dos grupos hegemônicos e dos formadores de opinião, que apagam a questão da variedade/heterogeneidade em favor de uma visão unificante de língua, a da variedade de prestígio, variedade linguística desses grupos.

A discussão em torno da língua correta, depurada de qualquer variação social, foi motivada pela distribuição pública do livro didático Por uma vida melhor, da coleção Viver e Aprender, destinado a alunos do segundo segmento da Educação de Jovens e Adultos. A Educação de Jovens e Adultos tem como público-alvo pessoas que não puderam estudar na idade certa, o que significa que são pessoas que, na sua grande maioria, pertencem às camadas mais pobres da população. Uma das formas de trazer de volta à escolarização formal essa parcela da população consiste em valorizar a sua cultura, o que, evidentemente, inclui a discussão da legitimidade e gramaticalidade dos falares populares, constitutivos de sua identidade. No capítulo intitulado Escrever é diferente de falar, os autores, ao tratarem da concordância, apresentam registros dos falares populares, como "Nós pega o peixe" e "Os menino pega o peixe", com o intuito de mostrar a variação social da língua portuguesa. Apesar de essa amostra ser ainda bastante tímida no que se refere à discussão da variação linguística e das relações de poder, e os autores reiterarem a necessidade do domínio da norma da variedade culta, aqui entendida como de prestígio, justamente considerando a questão de como a ideologia perpassa a língua e a questão do preconceito linguístico contra as camadas pobres da sociedade, a mídia, em sua grande maioria, apresentou uma valoração totalmente negativa da obra, acusando-a de incentivar o "uso errado" da língua portuguesa.

São exemplos de manchetes/títulos, veiculados pela mídia impressa: "Livro didático do MEC tem erro de português" (publicado pelo Jornal da Tarde, do grupo Estadão); “O assassinato da língua portuguesa; "Livro distribuído pelo MEC que tolera erros gramaticais como 'os livro' e 'nós pega' causa estragos no aprendizado de meio milhão de brasileiros e atrapalha o desenvolvimento do País" (publicado pela IstoÉ); "Livro didático faz a apologia do erro: exponho a essência da picaretagem teórica e da malvadeza dessa gente", publicado pela Veja).

A variação e a heterogeneidade de fenômenos intrínsecos à existência de uma língua passam a ser concebidas e valoradas como erros pela imprensa formadora de opinião. A plurivalência do signo, no caso, da variação social, é apagada em favor da língua única, por um processo de naturalização desse apagamento. Com ressalta Bakhtin (1998[1955]) ao discutir a questão da heterogeneidade linguística e da categoria/concepção de língua única, "a língua única expressa as forças de união e de centralização concretas, ideológicas e verbais, que decorrem da relação indissolúvel com os processos de centralização sócio-política e cultural.” (BAKHTIN, 1998[1975], p. 81). Uma das poucas vozes dissonantes na imprensa foi a de Luís Antônio Giron, em artigo publicado na Época: "Tudo isso me leva a pensar que grande parte da intelligentsia agiu ideologicamente ao abordar um assunto tão delicado. [...] Gente com diploma vistoso abandonou qualquer atitude minimamente científica para destilar o 
mais desavergonhado preconceito linguístico; leia-se: preconceito de classe. Desconfio de que a ascensão econômica e cultural das classes $C$ e D andam assustando certos defensores de privilégios, inclusive os linguísticos." Assim, pelo exemplo, podemos observar a relação constitutiva entre ideologia, valoração e linguagem.

Nas palavras de Ponzio (2008),

\begin{abstract}
Essa noção [ideologia] ocupa um lugar essencial em sua obra. Com o termo "ideologia" Bakhtin indica as diferentes formas de cultura, os sistemas superestruturais, como a arte, o direito, a religião, a ética, o conhecimento científico etc. (a ideologia oficial), e também os diferentes substratos da consciência individual, desde os que coincidem com a "ideologia oficial" aos da "ideologia não-oficial", aos substratos do inconsciente, do discurso censurado [...]. A ideologia é a expressão das relações histórico-materiais dos homens, mas “expressão" não significa somente interpretação ou representação, mas também significa organização, regularização dessas relações. [...] no signo ideológico está sempre presente uma "acentuação valorativa", que faz com que o mesmo não seja simplesmente expressão de uma "ideia", mas a expressão de uma tomada de posição determinada, de uma práxis concreta. (PONZIO, 2008, p. 112-115, grifos do autor).
\end{abstract}

Em síntese, uma vez estabelecida a relação constitutiva entre ideologia e signo/linguagem, observamos a postulação da dimensão axiológica/valorativa dos discursos, não havendo neutralidade nos discursos. Os enunciados, que materializam os discursos, apresentam sempre uma dimensão avaliativa e expressam um posicionamento social, como veremos na próxima seção. "Desse modo, qualquer enunciado é, na concepção de Círculo, sempre ideológico - para eles, não existe enunciado nãoideológico. E ideológico em dois sentidos: qualquer enunciado se dá numa esfera de uma das ideologias [...] e expressa sempre uma posição avaliativa [...].” (FARACO, 2003, p. 46-47, grifos do autor).

Por essa razão, ao tratar da relação entre língua, enunciado e interação, Volochinov (1986) afirma que

\begin{abstract}
$\mathrm{Na}$ realidade não são palavras o que pronunciamos ou escutamos, mas verdades ou mentiras, coisas boas ou más, importantes ou triviais, agradáveis ou desagradáveis, etc. $A$ palavra está sempre carregada de um conteúdo ou de um sentido ideológico [ideologia formalizada] ou vivencial [ideologia do cotidiano]. (VOLOCHINOV, 1986, p. 95, grifos do autor).
\end{abstract}

\title{
3 OS ENUNCIADOS E OS GÊNEROS:
} A MATERIALIZAÇÃO DO DISCURSO E DA VALORAÇÃO

A discussão inicial acerca do enunciado é apresentada pelo Círculo no texto $O$ discurso na vida e o discurso na arte, escrito em 1926. Bakhtin, ao refletir sobre o discurso na vida e na arte, defende o caráter social da arte, não abordado pelo método formal, que estudava apenas a forma material da obra. O método sociológico, que Bakhtin discute nesse texto, apresenta-se como alternativa ao método estritamente formalista de análise das obras. Como explica o autor: 
Os métodos que ignoram a essência social da arte tentam encontrar sua natureza e distinguir características apenas na organização do artefato são obrigados realmente a projetar a interrelação social do criador e do contemplador em vários aspectos do material e em vários procedimentos para estruturar o material. [...]. A comunicação estética, fixada numa obra de arte é, como já dissemos, inteiramente única e irredutível a outros tipos de comunicação ideológica. [...]. O que caracteriza a comunicação estética é o fato de que ela é totalmente absorvida na criação de uma obra de arte, e nas suas contínuas recriações por meio da co-criação dos contempladores, e não requer nenhum outro tipo de objetivação. Mas, desnecessário dizer, esta forma única de comunicação não existe isoladamente; ela participa do fluxo unitário da vida social, ela reflete a base econômica comum, e ela se envolve em interação e troca com outras formas de comunicação. (BAKHTIN, 1926, p. 4, grifos do autor).

A partir disso, para demonstrar suas observações acerca do método formal para o estudo da arte (em geral), Bakhtin (1926) apresenta uma análise dos enunciados da vida cotidiana, entendendo que, "na vida, o discurso verbal é claramente não autossuficiente. Ele nasce de uma situação pragmática extraverbal e mantém a conexão mais próxima possível com esta situação.” (p. 4). Sob essa perspectiva, o autor propõe que o enunciado não reflete passivamente (como um espelho) a situação extraverbal, ele está longe de ser sua causa externa, pois "conclui determinada situação" (RODRIGUES, 2005 , p. 161). É no extraverbal, compreendido como a sua dimensão social, que o caráter social do enunciado se constitui e se confirma, ou seja, que ocorre o trabalho da ideologia e da valoração que lhe é decorrente.

Em outras palavras, para Bakhtin (2003[1979], p. 280-283), o discurso, constituído no seio de uma dada esfera social, e por isso, refratado pela ideologia e pela valoração, materializa-se na forma de enunciados. Por isso, todo enunciado é concreto, irrepetível, historicamente individual, representa uma nova unidade (elemento) na comunicação discursiva, mas, ao mesmo tempo, é uma postura ativa (que é também uma reação-resposta a outros enunciados) do sujeito constituído socialmente e que se enuncia dentro de uma determinada esfera (BAKHTIN, 2003[1979]). Assim, para definir os enunciados como as unidades reais e concretas da interação e os diferenciar das unidades da língua vista como sistema, ele apresenta três características dos enunciados, que nos fazem observar também a relação entre esse conceito e a valoração:

(a) a alternância dos sujeitos do discurso: entre as palavras e as orações não há alternância de sujeitos, dado que esses conceitos são vistos no interior da língua, onde as fronteiras são de ordem gramatical. Já entre os enunciados há a alternância de sujeitos, uma vez que eles são as unidades de interação. Por isso, se entre palavras ou orações observa-se essa alternância, trata-se de enunciados compostos verbalmente de uma palavra e/ou uma oração. Todo falante termina seu enunciado para passar a palavra ao outro ou dar lugar a sua reação-resposta. Para Bakhtin (2003[1979]), o critério central característico da conclusibilidade do enunciado, como unidade concreta da comunicação discursiva, é a capacidade de determinar a ativa reação-resposta dos outros participantes da comunicação: todo enunciado suscita resposta(s), que é um ato de valoração sobre o enunciado do outro.

(b) a conclusibilidade específica do enunciado: entendida como o acabamento do enunciado a partir do seu interior, constitui-se como a possibilidade de o interlocutor tomar uma postura de resposta em relação ao enunciado do outro. Segundo o autor, a 
possibilidade de resposta, ou seja, a respondibilidade face ao enunciado do outro, materializa-se a partir da percepção do dixi conclusivo do autor, por parte do interlocutor, realizada a partir de três elementos ligados no todo orgânico do enunciado: (i) a exauribilidade semântico-objetal do tema: os temas são inesgotáveis, mas, ao se tornarem objetos de discurso, ou seja, ao entrarem no horizonte apreciativo e, logo, valorativo dos interlocutores, passam a ter acabamento dentro das condições/finalidades do enunciado, sendo esse acabamento percebido pelo interlocutor a partir da interação e do gênero do discurso; (ii) a intenção discursiva do discurso, ou seja, a vontade discursiva do falante, na medida em que esta, para Bakhtin, "determina o todo do enunciado, o seu volume e suas fronteiras" (BAKHTIN, 2003[1979], p. 281); e iii) os gêneros do discurso do enunciado: segundo o autor, os gêneros são balizas para a produção de enunciados e horizontes de expectativas (índices de interpretação) para o interlocutor. Assim, o gênero do discurso é outro elemento que permite a percepção do todo do enunciado e sua conclusibilidade. A escolha do gênero do discurso é determinada pela "especificidade de um dado campo da comunicação discursiva, por considerações semântico-objetais (temáticas), pela situação concreta da comunicação discursiva, pela composição pessoal dos seus participantes etc." (BAKHTIN, 2003[1979], p. 282). Conforme explica Bakhtin, apenas falamos e compreendemos o outro (seu discurso) por meio de gêneros do discurso, ou seja, o domínio dos gêneros é necessário para a interação. Assim, ao mesmo tempo em que podemos observar a conclusividade como um dos elementos de constituição do enunciado, também podemos observar nesse ato o trabalho da valoração, dado que tomar a palavra (que já é uma resposta, como dito) e/ou responder ao outro é posicionar-se axiologicamente face ao enunciado do outro.

(c) a expressividade: essa característica nos interessa mais de perto em função do objetivo deste trabalho, uma vez que a expressividade do enunciado e a valoração estão intimamente relacionados. Segundo Bakhtin (2003[1979], p. 289), "nos diferentes campos da comunicação discursiva, o elemento expressivo tem significado vário e grau vário de força, mas ele existe em toda parte: um enunciado absolutamente neutro é impossível." Essa propriedade de o enunciado ser expressivo é uma das marcas da posição valorativa dos participantes da comunicação discursiva face ao tema do enunciado e a eles próprios.

Além disso, para o autor, todo gênero do discurso requer um determinado tom, na medida em que sua construção inclui uma determinada valoração. Mesmo em gêneros mais formalizados e com alto grau de estabilidade, a entonação é elemento constitutivo 5 . Ainda no que se refere à relação entre valoração e entonação manifesta/concretizada nos gêneros, é possível a reacentuação de gêneros: por exemplo, a possibilidade de transferência da forma de gêneros com alto grau de estabilidade para forma de gêneros mais livres e mais criativos da comunicação discursiva oral, como da forma dos gêneros da saudação do campo oficial para o campo da comunicação familiar, com uma reacentuação irônico-paródica. Nesse caso, a reacentuação também age sobre a entonação. De fato, "pode-se transferir a forma de um gênero [de uma esfera para outra]; isto é, empregá-la como uma reacentuação irônico-paródica, com fins análogos 
pode-se misturar deliberadamente os gêneros das diferentes esferas." (BAKHTIN, 2003[1979], p. 284). Contudo, ressalta o autor, mesmo que alguns gêneros do discurso se prestem a uma reformulação livre e criadora, o seu uso criativo não funciona como a elaboração de um novo gênero. Embora mais plásticos e flexíveis do que as formas da língua, para os sujeitos falantes os gêneros são normativos (no sentido de regularidade de uso, resultado dos processos históricos) e usá-los criativamente demanda do falante o conhecimento da sua relativa estabilidade. Assim, esclarece Bakhtin (2003[1979]) que

\begin{abstract}
Quanto melhor dominamos os gêneros tanto mais livremente os empregamos, tanto mais plena e nitidamente descobrimos neles a nossa individualidade (onde isso é possível e necessário), refletimos de modo mais flexível e sutil a situação singular da comunicação; em suma, realizamos de modo mais acabado o nosso livre projeto de discurso. (BAKHTIN, 2003[1979], p. 285).
\end{abstract}

A partir dessa questão e considerando as discussões anteriores acerca da respondibilidade face ao enunciado do outro, retomamos as explicações de Bakhtin acerca do elemento expressivo do enunciado como a relação valorativa do falante face ao objeto do seu discurso e face aos outros enunciados. Por elemento expressivo o autor entende "a relação subjetiva emocionalmente valorativa do falante com o conteúdo do objeto e do sentido do seu enunciado." (BAKHTIN, 2003[1979], p. 289). Ressalta que é o elemento expressivo que determina o estilo e a composicionalidade do enunciado, isto é, a relação valorativa do falante com seu objeto de discurso e com os outros enunciados (já-ditos, pré-figurados ${ }^{6}$ ) leva à escolha dos recursos lexicais, gramaticais (estilo) e composicionais de seu enunciado. "A entonação expressiva é um traço constitutivo do enunciado." (BAKHTIN, 2003[1979], p. 290).

$\mathrm{O}$ autor explica que a expressividade é uma das características do enunciado, e que as palavras e orações, como unidades da língua na sua imanência, são desprovidas de entonação expressiva, pois, nesse caso, estamos diante de palavras e orações isoladas, no sistema da língua (em que estabelecem relação com outras palavras e orações), sem relação com a situação de interação. No entanto, essas palavras e orações adquirem sentido concreto quando se tornam parte de enunciados, isto é, quando se integram a uma determinada realidade concreta, em condições reais de comunicação discursiva. Assim, para Bakhtin (2003[1979]), escolhemos nossas palavras quando partimos do conjunto projetado do enunciado, ou seja, cada palavra que escolhemos é contagiada com a expressão valorativa do conjunto do enunciado.

\footnotetext{
escolhemos a palavra pelo significado que em si mesmo não é expressivo mas pode ou não corresponder aos nossos objetivos expressivos em face de outras palavras, isto é, em face do conjunto do nosso enunciado. O significado neutro da palavra referida a uma determinada realidade concreta em determinadas condições reais de comunicação discursiva gera a centelha da expressão. Ora, é precisamente isto que ocorre no processo de criação do enunciado [...] esta [centelha da expressão] não existe no sistema da língua [...]. (BAKHTIN, 2003[1979], p. 292).
}

\footnotetext{
${ }^{6}$ Por enunciados pré-figurados Bakhtin (1998[1975]) entende aqueles enunciados que o autor antecipa como sendo a possível ou desejada reação-resposta do interlocutor.
}

PEREIRA, Rodrigo Acosta; RODRIGUES Rosângela Hammes. O conceito de valoração nos estudos do círculo de Bakhtin: a inter-relação entre ideologia e linguagem. Linguagem em (Dis)curso - LemD, Tubarão, SC, v. 14, n. 1, p. 177-194, jan./abr. 2014. 
Com isso, podemos entender que é só no contato do significado linguístico com a realidade concreta, só na penetrabilidade da língua com a realidade que se gera a centelha da expressão. Como vimos, para o autor, a centelha da expressão não existe nem no sistema da língua, nem na realidade objetiva fora de nós: a emoção, o tom, os juízos de valor somente surgem e se materializam no emprego vivo da língua, em um enunciado concreto e real.

Além disso, Bakhtin (2003[1979]) afirma que o enunciado constitui-se também em função do seu auditório, ou seja, todo enunciado dirige-se a um interlocutor, que influencia também nos limites estilísticos dos enunciados e na sua expressividade. Partindo desta questão e da discussão anterior sobre as particularidades dos enunciados, Bakhtin (2003[1979]) entende que a situação social de interação se integra ao enunciado, não se apresentando como mera causa deste: todo enunciado é inteiramente determinado pelas relações sociais. "A situação social mais imediata e o meio social mais amplo determinam completamente e, por assim dizer, a partir do seu próprio interior, a estrutura da enunciação." (VOLOCHINOV, 1988[1929], p. 113, grifos do autor).

O que o Círculo de Bakhtin procura esclarecer é que qualquer que seja o enunciado, da mais íntima saudação do dia a dia a um romance dostoievskiano, ele é sempre um enunciado socialmente dirigido. Com isso, para Volochinov, o enunciado não poderá, de forma alguma, ser explicado fora da situação social, na medida em que "a comunicação verbal entrelaça-se inextricavelmente aos outros tipos de comunicação e cresce com eles sobre o terreno comum da situação de produção" (VOLOCHINOV, 1988[1929], p. 124). Entendemos, assim, que o enunciado é concebido não apenas como uma unidade de comunicação, mas como uma unidade de sentido axiologicamente constituída na situação interativa. O enunciado, dessa forma, é compreendido sempre sob o ponto de vista social, histórico e cultural, que "inclui, para efeito de compreensão e análise, a comunicação efetiva e os sujeitos e discursos nele envolvidos" (BRAIT; MELO, 2007, p. 65).

De acordo com Bakhtin (2003[1979]), a enunciação é sempre considerada do ponto de vista de um falante em relação necessária com o ouvinte. $\mathrm{O}$ ouvinte, ao entrar em situação de interação com o enunciado do outro, ocupa simultaneamente em relação a este enunciado uma posição responsiva axiologicamente marcada: uma posição de resposta, uma reação-resposta valorada face ao(s) enunciado(s) do outro. Para o autor, essa atitude de resposta se forma ao longo de todo o processo interlocutivo, na medida em que "toda compreensão da fala viva, do enunciado vivo é de natureza ativamente responsiva [...]; toda compreensão é prenhe de resposta, e nessa ou naquela forma a gera obrigatoriamente: o ouvinte se torna falante." (BAKHTIN, 2003[1979], p. 271).

Além disso,

O empenho em tornar inteligível a sua fala é apenas o momento abstrato do projeto concreto e pleno de discurso do falante. Ademais, todo falante é por si mesmo um respondente em maior ou menor grau: porque ele não é o primeiro falante, o primeiro a ter violado o eterno silêncio do universo, e pressupõe não só a existência do sistema da língua que usa mas também de alguns enunciados antecedentes - dos seus e alheios - com os quais o seu enunciado entra nessas ou naquelas relações [...]. Cada enunciado é um elo na corrente complexamente organizada de outros enunciados. (BAKHTIN, 2003[1979], p. 272). 
Volochinov (1981[1926]) sustenta que há um vínculo efetivo entre enunciado e situação social, isto é, a situação se integra ao enunciado, constitui-se como uma parte dele, indispensável para a compreensão do seu sentido. Por isso, para o autor, a expressividade, o tom valorativo, quaisquer que sejam os critérios que o regem (ético, político, científico), leva em consideração não apenas o que se está incluído nos fatores estritamente verbais (unidades da língua), mas abrange toda a situação extraverbal do enunciado. Esse tom se funde no todo do enunciado, envolvendo diretamente um dado evento da vida, fundindo-se nesse evento, formando uma unidade indissolúvel. Essa unidade se constrói no contexto extraverbal do enunciado, que é composto de três elementos indissociáveis: (i) o horizonte espacial e temporal comum dos interlocutores, o que o autor chama de unidade do visível; (ii) o conhecimento e a consequente compreensão comum da situação interativa; e (iii) a avaliação comum dessa situação.

A unidade do visível, o horizonte espaçotemporal, diz respeito ao que é conjuntamente visto, o que pode ser captado na sua real e viva contemplação, o que está diretamente relacionado ao que se pode compreender comumente entre os interlocutores, o que se pode, por assim dizer, conjuntamente saber. Com isso, o "conjuntamente visto" e o "conjuntamente sabido" se integram ao "unanimemente avaliado", o horizonte axiológico/valorativo da situação extraverbal, onde os interlocutores compreendem a entonação, a expressividade do enunciado.

Segundo destaca Rodrigues (2001), para o Círculo o vínculo entre o enunciado (sua dimensão verbal/semiótica) e a situação social concretiza-se pela entonação.

\begin{abstract}
Através dela, o discurso se orienta para fora dos seus limites verbais e entra em contato com a vida sócio-ideológica. Ela se situa na fronteira da vida social e da parte verbal do enunciado, marcando a atitude valorativa (feliz, aflita, interrogativa, de admiração, de surpresa etc.). [...]. Pela entonação o falante se engaja socialmente e toma posição ativa em relação a certos valores. (RODRIGUES, 2001, p. 27).
\end{abstract}

Por essa razão, para Bakhtin,

\begin{abstract}
Um enunciado isolado e concreto sempre é dado num contexto cultural e semânticoaxiológico (científico, artístico, político, etc.) ou no contexto de uma situação isolada da vida privada; apenas nesses contextos o enunciado isolado é vivo e compreensível: ele é verdadeiro ou falso, belo ou disforme, sincero ou malicioso, franco, cínico, autoritário e assim por diante. (BAKHTIN, 1998[1975], p. 46).
\end{abstract}

Entretanto, essa concepção de entonação não deve levar a pressupor que ela seja algo do âmbito do individual, no sentido de não entrar no âmbito do social. Para a sua existência, ela tem necessidade de sustentação coletiva. "É a materialização de uma avaliação social, a expressão 'sonora' da valoração, sendo, portanto, toda entonação expressiva. Sensível às mais elementares mudanças sociais, é na entonação do enunciado que a avaliação social encontra antes de tudo sua expressão." (RODRIGUES, 2001, p. 27).

Após a discussão acerca da constitutividade dos enunciados e da relação entre eles e a valoração, passamos a abordar o conceito de cronotopo, na medida em que procuramos entender a valoração e sua expressividade no enunciado, já iniciada nesta seção, mas agora à luz da relação entre espaço e tempo, ou, de modo mais preciso, em relação à sua dimensão social. 
Bakhtin (2003[1979]; 2008b[1965]), ao discutir as questões acerca do discurso no romance, concebe os gêneros do discurso, em especial os gêneros literários, como modos específicos de pensamento, maneiras de pensar sobre o mundo. Para o autor, o gênero romance sustenta a relação entre as pessoas e os eventos no tempo e no espaço, apresentando-se como uma forma novelística da matriz espaçotemporal. $\mathrm{O}$ estudo do cronotopo, sob essa perspectiva, apresenta-se como a forma de apreender $\mathrm{e}$ compreender as experiências sociais, históricas e culturalmente construídas.

Entendendo que todas as situações sociais de interação são constituídas por uma instância definida de tempo e de espaço, Bakhtin preocupou-se em entender o cronotopo como a representabilidade dos eventos e da imagem de homem. É como se o cronotopo determinasse, por assim dizer, parâmetros específicos para os eventos, construídos a partir de conceitos também específicos de sociedade, de história e de cultura. Para o autor, o gênero do discurso e seu cronotopo fazem parte da compreensão das ações e dos eventos de uma sociedade particular, na medida em que dessa relação podemos entender as ações humanas. Sob essa perspectiva, Bakhtin (2008b[1965]) estuda, por exemplo, as festas populares e o carnaval como imagens construídas por Rabelais em relação à realidade de seu tempo.

Bakhtin procura no conceito de cronotopo investigar o equilíbrio entre as dimensões do espaço e do tempo, objetivando compreender como esse conceito realiza, de certa forma, a fusão dos índices espaço-temporais em um todo inteligível e concreto. O conceito de cronotopo aliado ao conceito de valoração nos leva a entender o que para o autor se define como a matriz espaçotemporal de onde os vários acontecimentos se realizam, se materializam e significam. Entendendo que a concretização desses acontecimentos se dá na forma de enunciados, e estes, por sua vez, nos diversos campos sociais de atividades, se organizam na forma de gêneros, podemos compreender que os gêneros do discurso constroem visões do homem e de sua realidade, de onde se derivam valores.

Como explica Bakhtin (2003[1979]), os gêneros do discurso são formas sociais típicas constituídas historicamente, modos sociais de dizer, modos de pensar sobre o real, consequentemente, projetam, à luz de determinados valores, visões sócio-históricoculturais diversas. Ao compreendermos, portanto, que o cronotopo apresenta a visão de homem em suas relações social, espaço e temporalmente localizadas na história e na cultura, e ao retomarmos Bakhtin (1998[1975], p. 305) e sua explicação acerca da exteriorização do homem pela palavra, podemos, de fato, compreender que o cronotopo nos apresenta não apenas uma visão de homem social, mas uma visão axiológica e ideologicamente constituída da realidade de seu tempo. Essa visão de homem se constrói seja em função do próprio quadro específico de representação desse homem (como, por exemplo, faz Rabelais à luz de um realismo grotesco ou Dostoiévski, sob a perspectiva da polifonia), seja em relação ao estudo de seu discurso, na medida em que, "para entrar em nossa experiência (experiência social, inclusive), [os] significados, quaisquer que eles sejam, devem receber uma expressão espaço-temporal qualquer, ou seja, uma forma sígnica audível e visível por nós [...].” (BAKHTIN, 1998[1975], p. 
361-362). Assim, para Bakhtin, a cada nova temporalidade, ascendem novos valores, novas possibilidades e, com estes, um novo homem. É a renovação dos sentidos do passado e a criação de sentidos futuros, como esclarece Amorim (2006, p. 104). O tempo é o elemento do dinâmico, do movimento e da transformação que, indissoluvelmente ligado ao espaço, consubstancia o campo dos acontecimentos. De acordo com a autora,

O conceito de cronotopo trata de uma produção da história. Designa um lugar coletivo, espécie de matriz espaço-temporal de onde as várias histórias se contam ou se escrevem. Está ligado aos gêneros e a sua trajetória. Os gêneros são formas coletivas típicas, que encerram temporalidades típicas e assim, consequentemente, visões típicas de homem. (AMORIM, 2006, p. 105).

O cronotopo é, portanto, responsável pela imagem-demonstração dos acontecimentos: o espaço, o tempo, os participantes, a situação imediata, a situação ampla, graças "justamente à condensação e concretizações espaciais dos índices de tempo em regiões definidas do espaço.” (BAKHTIN, 1998[1975], p. 355). O cronotopo, de fato, realiza as indicações precisas sobre o lugar e o tempo históricos da realização do gênero.

Entendemos, a partir disso, que o cronotopo em cada gênero nos apresenta uma imagem de homem, isto é, uma determinada visão da história, da cultura, das pessoas, das experiências e da realidade. Como já visto, os gêneros do discurso são conceptualizações da realidade, isto é, os gêneros "são modos específicos de visualizar uma dada parte da realidade situada no tempo-espaço" (MORSON; EMERSON, 2008, p. 290). Como afirma Bakhtin (1985[1928], p. 134),

\footnotetext{
nós pensamos e conceituamos em enunciados, e os enunciados, em última análise, são formulados, não de acordo com princípios sintáticos, mas segundo princípios genéricos. Dir-se-ia [portanto] que a consciência humana possui uma série de gêneros interiores para ver e conceitualizar a realidade. [...] À medida que aprendemos novos gêneros, aprendemos a ver diferentemente e expandimos nosso repertório de visão [...] novos aspectos da realidade visível.
}

Assim, podemos entender que as experiências humanas são situadas no tempoespaço e, dessa forma, as pessoas necessitam aprender continuamente novos gêneros, à medida que o âmbito espaçotemporal das suas experiências culturais se expande. Além disso, cada gênero é adaptado para conceptualizar alguns aspectos da realidade, isto é, "cada gênero só é capaz de controlar certos aspectos definidos das experiências. Cada gênero possui princípios definidos de seleção [...] e um escopo e profundidade de penetração definidos no tempo-espaço" (BAKHTIN, 1985[1928], p. 131). Ainda, podemos entender que o cronotopo se caracteriza como o tempo-espaço das atividades humanas, o campo para a representabilidade das experiências sociais. "É como se cada gênero possuísse um 'campo' específico que determinasse os 'parâmetros' dos eventos [...]. Estudar o campo é estudar o cronotopo.” (MORSON; EMERSON, 2008, p. 387). É nesse sentido que Rodrigues (2001) afirma que cada gênero do discurso se assenta em um dado cronotopo, que pode ser relacionado com a situação social de interação de cada gênero. 
Com isso, a nosso ver, há uma relação inextricável entre o tempo, o espaço e os valores que perpassam, constituem ou se confrontam nessa relação. O estudo do cronotopo, a partir disso, possibilita descobertas múltiplas sobre a relação entre as pessoas, seus enunciados, os valores que carregam em seus enunciados e seus eventos. Além disso, podemos entender que o cronotopo, mais do que ser apenas responsável pela orquestração indissolúvel do tempo e espaço presente nos eventos do homem, é, de fato, o campo de visão axiologicamente marcado para esses eventos.

Em síntese, o cronotopo organiza significativamente os acontecimentos e, dessa forma, a própria situação de interação. $\mathrm{O}$ cronotopo, de fato, concretiza as indicações precisas sobre o lugar e o tempo da realização do gênero e dos enunciados. Além disso, para o autor, o cronotopo pode incluir em si atravessamentos de outros cronotopos, na medida em que, em determinados casos, um cronotopo "englobador ou dominante" (BAKHTIN, 1998[1975] p. 357) estabelece relações complexas e específicas com outros cronotopos. Os cronotopos podem se incorporar uns aos outros, coexistirem, se entrelaçar, permutar, confrontar-se, opor-se ou se encontrar nas inter-relações mais complexas $^{7}$. Como conclui Bakhtin (1998[1975]), sem a expressão espaçotemporal, mesmo o pensamento mais abstrato é impossível; dessa forma, toda entrada no campo dos sentidos e dos valores que neles se constroem só acontece pela porta do cronotopo.

\title{
5 AS RELAÇÕES DIALÓGICAS: O ENCONTRO E O CONFRONTO DAS VALORAÇÕES
}

Como esclarecem Faraco (2003) e Morson e Emerson (2008), a concepção dialógica de linguagem foi crucial para o pensamento de Bakhtin a partir de 1924. É o período em que o autor forma suas bases para os estudos sobre a psique, a cultura e a teorização discursiva sobre o romance. Conforme os autores explicam, Bakhtin não desejava simplesmente acrescentar um posicionamento dialógico aos estudos da poética, da estilística e da linguística de sua época, mas procurava compreender a natureza dialógica da linguagem. Acerca da questão, os autores observam que o termo dialogismo e seus derivados diálogo, dialógico, dialogização, acabaram por incorporar, em excedentes de visão teóricos diversos, equívocos de interpretação, resultando em vários usos inapropriados e incoerentes dessa ideia bakhtiniana, muitas vezes vista como diálogo face a face.

Como observa Faraco,

\begin{abstract}
Nesse sentido, é interessante lembrar que aquilo que Bakhtin chama de relações dialógicas não remete ao diálogo face a face (como muitos acreditam), mas à dinâmica de múltiplas inter-relações responsivas entre posições socioavaliativas. Na interação vista pelo olhar bakhtiniano, não se trocam mensagens, mas se dialogizam axiologias. (FARACO, 2005, p. 219 , grifos do autor).
\end{abstract}

\footnotetext{
${ }^{7}$ Por exemplo: um romance que incorpora o gênero diário íntimo, um artigo assinado escrito redigido como sendo uma carta. Vemos, nesses dois casos, enunciados de dados gêneros (romance e artigo assinado), com seus respectivos cronotopos, incorporarem cronotopos de outros gêneros (diário íntimo e carta).
} 
Faraco salienta que Bakhtin apresenta a interação como constitutiva da condição humana. O sujeito se constitui na relação que estabelece com o outro, por meio da interação. Sua individualidade se estabelece pela alteridade. No entanto, essa interação não pode ser vista como realizada por meio de sujeitos individuais, no sentido de sujeitos autossuficientes. Na percepção do autor, "Bakhtin inova as análises da interação ao entendê-la não como o encontro fortuito de mônadas autossuficientes que trocam mensagens sustentadas pelo código, mas como o encontro de posições socioaxiológicas." (FARACO, 2005, p. 219).

A partir dessas considerações, no presente estudo focalizaremos a natureza dialógica do enunciado sob a perspectiva das relações dialógicas que se estabelecem entre os enunciados e, por consequência, seus determinados horizontes axiológicos/valorativos.

Bakhtin (2003[1979]) explica, como já comentado quando da discussão da expressividade, que todo enunciado é pleno de ressonâncias e ecos de outros enunciados. Os enunciados não são indiferentes uns com os outros, pois se conhecem e se atravessam mutuamente. Além disso, essas relações com os enunciados do outrem e, por conseguinte, com seus juízos de valor (quaisquer posições valorativas), determinam o todo do enunciado.

Bakhtin (2003[1979]) explica que as relações dialógicas, como já dito, são relações de sentido que se realizam nos enunciados. De acordo com o autor, dois enunciados, ao se confrontarem em um dado plano de sentido, em dada situação de interação, acabam sempre por estabelecer relações dialógicas, que, para o autor, são relações semântico-axiológicas. Além disso, para o autor, devemos entender que as relações dialógicas são, por natureza, extraverbais, contudo não podem, simultaneamente, ser separadas do discurso. Bakhtin (1998[1975]; 2003[1979]; 2008a[1929]) nos lembra que as relações dialógicas são possíveis não apenas entre enunciados integrais, mas também: (a) com qualquer parte significante do enunciado; (b) entre estilos de língua, dialetos sociais; e (c) com a enunciação como um todo, desde que essas partes sejam vistas como o todo do enunciado que representam. $\mathrm{O}$ autor (2008a[1929]) assim esclarece essa questão:

\footnotetext{
As relações dialógicas são possíveis não apenas entre enunciações integrais (relativamente), mas o enfoque dialógico é possível a qualquer parte significante do enunciado [...], se ouvimos nela a voz do outro. Por isso, as relações dialógicas podem penetrar no âmago do enunciado [...], por outro lado, as relações dialógicas são possíveis entre os estilos de linguagem [...]. Por último, as relações dialógicas são possíveis também com a própria enunciação como um todo [...]. (BAKHTIN, 2008a[1929], p. 210-211).
}

Com referência às relações dialógicas com qualquer parte significante do enunciado, Bakhtin (2008a[1929]) entende as relações de sentido valorativamente construídas no interior do enunciado ou mesmo no interior de uma palavra, desde que possamos entender que aí se encontram duas posições de valor, duas vozes que colidem. $\mathrm{O}$ autor define as relações dialógicas entre estilos de língua, dialetos sociais como relações semântico-valorativas em que é possível perceber cosmovisões de linguagem que se entrecruzam, isto é, duas visões de mundo e seus valores correspondentes 
parecem, por assim dizer, se confrontar. As relações dialógicas com a própria enunciação como um todo, por sua vez, para Bakhtin (2008a[1929]), podem ocorrer em partes isoladas desse todo ou com uma palavra isolada nele, desde que, por algum modo, possamos nos separar dessas relações, desde que sejamos capazes de manter distância face a elas, ou seja, que representem diferentes vozes e suas valorações. Para o autor, é o caso, por exemplo, do discurso bivocal, onde a palavra tem duplo sentido, voltado para o objeto do discurso (como palavra comum) e para um outro discurso.

Bakhtin (2003[1979]) discute a questão dos tipos e graus de alteridade da palavra alheia e as diferentes formas de relação com ela, além dos diversos meios de sua exclusão da vida do discurso. Sob essa perspectiva, afirma que a palavra do outro é sempre de índole essencialmente dialógica, que se constitui no encontro de duas consciências. Para o autor, "tudo o que diz respeito, a começar pelo meu nome, chega do mundo exterior à minha consciência pela boca dos outros, com sua entonação, sua tonalidade valorativo-emocional. A princípio, eu tomo consciência de mim através dos outros [...]." (BAKHTIN, 2003[1979], p. 373, grifos nossos). Em outras palavras, "como o corpo se forma inicialmente no seio (corpo) materno, assim a consciência do homem desperta envolvida pela consciência do outro." (BAKHTIN, 2003[1979], p. 373-374). Além disso, segundo o autor, podemos compreender que todas as palavras, além das minhas, são, por natureza, palavras do outro. $\mathrm{Na}$ verdade, em termos bakhtinianos, vivemos no mundo de palavras do outro, e a nossa vida é orientada nesse mundo multivocalizado. Reagimos a todo momento às palavras do outro; a própria compreensão se constrói dessa reação, como explica o autor: "compreensão e avaliação. É impossível uma compreensão sem avaliação. Não se pode separar compreensão e avaliação: elas são simultâneas e constituem um ato único integral." (BAKHTIN, 2003[1979], p. 378, grifos nossos). O sentido é de índole responsiva, é uma reaçãoresposta ao enunciado de outrem. Como explica Bakhtin (2003[1979], p. 381-382), "chamo sentido às respostas a perguntas. Aquilo que não responde a nenhuma pergunta não tem sentido para nós. [...] Um sentido atual não pertence a um só sentido, mas tãosomente a dois sentidos que se encontraram e se contactaram."

Para Bakhtin, em cada época, em cada percurso da história, os enunciados são construídos a partir de determinados valores, que se entrecruzam e se enriquecem com outros sentidos, à medida que o curso da história absorve outras projeções. Em cada época, em cada campo de atividade e em cada círculo social, os enunciados são construídos e reconstruídos, à medida que valores são ressignificados. Essa ressignificação não apenas opera no curso da projeção sócio-histórico-cultural, mas, essencialmente, na interação contínua com os enunciados do outro.

Sob essa perspectiva, Bakhtin (1998[1975]) afirma que a orientação dialógica é naturalmente um fenômeno do discurso; trata-se da natureza de todo discurso vivo. Como argumenta o autor, em todos os caminhos do discurso, em suas múltiplas direções, este se abre a um multidiscurso social, o diálogo social circunstante. É a concentração de vozes multidiscursivas, impregnadas pela plenitude das ressonâncias dialógicas e entoações multissonantes do plurilinguismo. "Em todos esses caminhos até o objeto, em todas as direções, o discurso se encontra com o discurso de outrem e não pode deixar de participar, com ele, de uma interação viva e tensa." (BAKHTIN, 1998[1975], p. 88). Com isso, podemos entender que a concepção de discurso, em suas múltiplas direções, é sempre dialógica. 
Em resumo, as relações dialógicas são relações semântico-axiológicas inerentes ao discurso, isto é, relações que fazem parte da natureza do discurso. Como observa Amorim (2004, p. 140), "o dialogismo de um enunciado é um acontecimento; não é uma simples experiência psíquica nem uma relação lógica. Mesmo se as relações dialógicas são impossíveis sem relações lógicas, a elas não se reduz[em].” Dialogismo pressupõe acontecimento, isto é, enunciados que, como atos singulares e irrepetíveis, engendram-se em relações semântico-valorativas, socialmente orientadas.

\section{CONSIDERAÇÕES FINAIS}

Neste texto, objetivamos revisitar os escritos do Círculo de Bakhtin, procurando compreender o conceito de valoração. Para tanto, perpassamos por diferentes caminhos: a construção material e a marca valorativa da(s) ideologia(s) no discurso, a expressividade dos enunciados e dos gêneros, a construção axiologicamente projetada do homem e do mundo pelo cronotopo e as relações semântico-valorativas que se engendram nos enunciados.

Nesse percurso, pudemos observar como o conceito de valoração está presente no conjunto das obras do Círculo, seja à luz da ideologia e dos enunciados e dos gêneros, seja na constitutividade do cronotopo e das relações dialógicas. Além disso, vimos que a valoração é indissociável do discurso, da sua constitutividade histórica, ideológica e cultural. Com isso, percebemos que a valoração não apenas é compreendida e considerada sob a perspectiva da situação imediata das práticas discursivas, como pelas conjecturas sócio-histórico-culturais constitutivas desse contexto. $\mathrm{O}$ conceito de valoração, portanto, tem papel importante nos estudos do Círculo, justamente porque, dentre outros conceitos, segue a compreensão do grupo de construir suas reflexões sob o ponto de vista histórico, cultural e social na procura de uma teoria enunciativodiscursiva da linguagem.

Entendemos, dessa forma, que o próprio conceito de valoração, à luz da teorização bakhtiniana, somente pode ser entendido quando relacionado aos outros conceitos-chave no conjunto da obra do Círculo. A partir disso, procuramos propor uma discussão em que pudéssemos relacionar a valoração com os conceitos de ideologia, enunciado, gêneros do discurso, cronotopo, dialogismo, entendendo esse percurso de estudo como uma entre outras rotas de acesso ao conceito de valoração.

\section{REFERÊNCIAS}

AGUIAR, C. A. de et al. Por uma vida melhor. Língua Portuguesa. São Paulo: Global, 2011.

AMORIM, M. O pesquisador e seu outro: Bakhtin nas ciências humanas. 2. reimpr. São Paulo: Musa Editora, 2004.

Cronotopo e exotopia. In: BRAIT, B. (Org.). Bakhtin: outros conceitos-chave. São Paulo: contexto, 2006, p. $95-114$.

BAKHTIN, M. M. Problemas da poética de Dostoiévski. Tradução do russo por Paulo Bezerra. 4. ed. rev. Rio de Janeiro: Forense Universitária, 2008a[1929]. 
- Cultura popular na Idade Média e no Renascimento: o contexto de François Rabelais. Tradução de Yara Frateschi Vieira. 6. ed. São Paulo/Brasília: Hucitec, 2008b[1965].

- Estética da criação verbal. Tradução do russo por Paulo Bezerra. 4a. ed. São Paulo: Martins Fontes, 2003[1951/1953].

- Questões de literatura e de estética: a teoria do romance. Tradução do russo por Aurora F. Bernadini, José P. Júnior, Augusto G. Júnior et al. 4. ed. São Paulo: Ed. Unesp/Hucitec, 1998[1975]. BAKHTIN, M. M.; VOLOSCHINOV, V. N. Discurso na vida e discurso na arte (sobre a poética sociológica).Trad. de Carlos Alberto Faraco e Cristóvão Tezza [para fins didáticos]. Versão da língua inglesa de I. R. Titunik a partir do original russo, 1926.

BAKHTIN, M. M.; MEDVEDEV, p. N. The formal method in literary scholarship. A critical introduction to sociological poetics. Cambridge: H.U.P, 1985 [1928].

BRAIT, B.; MELO, R. Enunciado/enunciado concreto/enunciação. In: BRAIT, B. (Org.). Bakhtin: conceitos-chave. São Paulo: Contexto, 2007, p. 61-78.

FARACO, C. A. Interação e linguagem: balanço e perspectivas. Calidoscópio, v. 3, n. 3, p. 214-221, set./dez.2005. Disponível em:

$<$ http://www.unisinos.br/publicacoes_cientificas/images/stories/pdfs_calidoscopio/vol3n3/art08_faraco.p df>. Acesso em: ago. 2010.

Linguagem \& diálogo: as idéias do Círculo de Bakhtin. Curitiba: Criar Edições, 2003.

MIOTELLO, V. Ideologia. In.: BRAIT, B. (Org.). Bakhtin: conceitos-chave. 4. ed. São Paulo: Contexto, 2008[2001]. p. 167-176.

MORSON, G. S; EMERSON, C. Mikhail Bakhtin: a construção de uma prosaística. Tradução de Antonio de Pádua Danesi. São Paulo: EDUSP, 2008.

PONZIO, A. A revolução bakhtiniana: o pensamento de Bakhtin e a ideologia contemporânea. Tradução do italiano por Valdemir Miotello. São Paulo: Contexto, 2008.

RODRIGUES, R. H. A constituição e o funcionamento do gênero jornalístico artigo: cronotopo e dialogismo. 2001. 347f. Tese (Doutorado em Lingüística Aplicada e Estudos da Linguagem) - Programa de Estudos Pós-Graduados em Lingüística Aplicada e Estudos da Linguagem (LAEL), Pontifícia Universidade Católica de São Paulo, São Paulo.

Os gêneros do discurso na perspectiva dialógica da linguagem: A abordagem de Bakhtin. In: MEURER, J. L; BONINI, A.; MOTTA-ROTH, D. (Orgs.). Gêneros: teorias, métodos e debates. São Paulo: Parábola, 2005. p. 152-183.

VOLOSHINOV, V. N. ¿Qué es el lenguaje? Tradução do italiano de Ariel Bignami. In.: SILVESTRI, A.; BLANCK, G. Bajtín y Vigotsky: la organización semiótica de la conciencia. Barcelona: Anthropos, 1993[1929]. p. 217-243.

. Marxismo e filosofia da linguagem: problemas fundamentais do método sociológico na ciência da linguagem. Tradução do francês de Michel Lahud e Yara F. Vieira. 4. ed. São Paulo: Hucitec, 1988[1929].

Le discours dans la vie et le discours dans la poésie. Contribution à une poétique sociologique. Tradução do russo por Georges Philippenko. In.: TODOROV, T. Mikhaïl Bakhtine: le principe dialogique - suivi de Écrits du cercle de Bakhtine. Paris: Éditions du Seuil, 1981. p. 181-215.

Les frontières entre poétique et linguistique. Tradução do russo por Georges Philippenko. In: TODOROV, T. Mikhaïl Bakhtine: le principe dialogique - suivi de Écrits du cercle de Bakhtine. Paris: Éditions du Seuil, 1981. p. 243-285.

Recebido em: 18/02/12. Aprovado em: 15/12/12.

Title: The concept of appraisal in Bakhtin's Circle studies: the inter-relationship between ideology and language

Authors: Rodrigo Acosta Pereira; Rosângela Hammes Rodrigues

Abstract: The present essay aims at discussing the concept of appraisal in the writings of Bakhtin's Circle. To do so, we revisit the Circle works by seeking to demonstrate the constitutive relationship between this concept and the concepts of ideology and language. The research leads us to understand the appraisal as social value indexes and ideology as the axiological horizon of the discourse, while understanding the utterances and the

PEREIRA, Rodrigo Acosta; RODRIGUES Rosângela Hammes. O conceito de valoração nos estudos do círculo de Bakhtin: a inter-relação entre ideologia e linguagem. Linguagem em (Dis)curso - LemD, Tubarão, SC, v. 14, n. 1, p. 177-194, jan./abr. 2014. 
discourse genres as the materialization of appraisal and ideology. The study is is based on the review of literature and aims at helping to understand the concept of appraisal and its relation to the concepts of ideology and language, among other aspects, which are engendered in Bakhtin's work.

Keywords: Bakhtin's Circle. Appraisal. Ideology. Language.

Título: El concepto de valoración en los estudios del Círculo de Bakhtin: la interrelación entre ideología y lenguaje

Autores: Rodrigo Acosta Pereira; Rosângela Hammes Rodrigues

Resumen: Ese trabajo objetiva discutir el concepto de valoración en escritos del Círculo de Bakhtin. Para tanto fueron revisitadas las obras del Círculo, procurando demostrar la relación constitutiva de ese concepto con los de ideología y lenguaje. La investigación conduce a entender la valoración como índices sociales de valor, y la ideología como el horizonte axiológico del discurso, allá más de entender la enunciación y los géneros como materialización de valoración y de ideología. El estudio se construye esencialmente por medio de revisión bibliográfica y busca colaborar para el entendimiento del concepto de valoración y su relación con los de ideología y lenguaje, entre otros que se engendran en la obra de Bakhtin.

Palabras-clave: Círculo de Bakhtin. Valoración. Ideología. Lenguaje. 